\title{
Prática alimentar entre crianças menores de dois anos de idade residentes em municípios do semiárido do Estado da Paraíba, Brasil
}

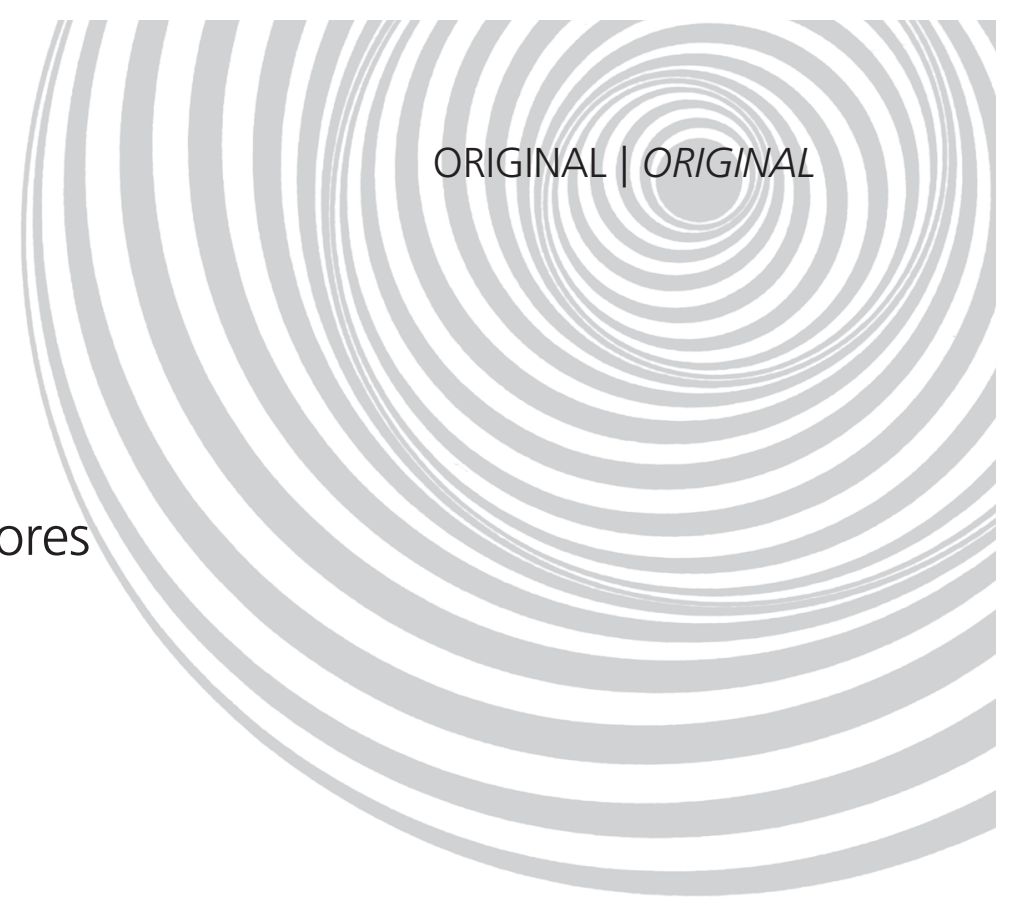

\author{
Feeding practice among children under \\ 24 months in the semi-arid \\ area of Paraíba, Brazil
}

Poliana de Araújo PALMEIRA ${ }^{1}$

Sandra Maria Chaves dos SANTOS²

Rodrigo Pinheiro de Toledo VIANNA ${ }^{3}$

RE S U M O

\section{Objetivo}

Analisar a prática alimentar de crianças menores de dois anos de idade residentes em municípios do interior do Estado da Paraíba.

\section{Métodos}

Estudo secional realizado nos 14 municípios mais carentes do Estado da Paraíba. Foram pesquisados 539 domicílios com pelo menos uma criança com idade entre 0 e 23,9 meses. Aplicou-se às mães recordatório 24 horas sobre alimentação das crianças. O modelo de análise considerou três momentos do crescimento e desenvolvimento da criança, identificando as recomendações de consumo alimentar pertinentes.

\section{Resultados}

Crianças de 0-5,9 meses: destacou-se um importante percentual de desmame (20,7\%) e a reduzida prevalência do aleitamento materno exclusivo (30,5\%). Crianças de 6-11,9 meses: 45,2\% ainda mamavam, porém apenas $21,7 \%$ das crianças entre 6 e 9,9 meses apresentaram uma alimentação complementar oportuna. Crianças entre 12-23,9 meses: a prática alimentar das crianças caracterizou-se essencialmente pelo consumo de leite não materno e pelo consumo insuficiente de alimentos fontes de ferro.

\footnotetext{
1 Universidade Federal de Campina Grande, Centro de Educação em Saúde, Unidade Acadêmica de Saúde, Curso de Nutrição. Sítio Olho D’agua da Bica, s/n., 50175-000, Cuité, PA, Brasil. Correspondência para/Correspondence to: P.A. PALMEIRA. E-mail: <polipalmeira@ufcg.edu.br>.

${ }^{2}$ Universidade Federal da Bahia, Escola de Nutrição, Departamento da Ciência da Nutrição. Salvador, BA, Brasil.

${ }^{3}$ Universidade Federal da Paraíba, Centro de Ciências da Saúde, Departamento de Nutrição. João Pessoa, PA, Brasil.
} 
554 | P.A. PALMEIRA et al.

\section{Conclusão}

O hábito alimentar distancia-se de uma prática alimentar segura, especialmente pela interrupção precoce do aleitamento materno exclusivo e sua consequente substituição por refeições à base de leite não materno, expondo esse grupo a situações de insegurança alimentar e nutricional.

Termos de indexação: Consumo de alimentos. Saúde materno-infantil. Segurança alimentar e nutricional.

\section{A B S T R A C T}

\section{Objective}

Examine the feeding practices among children under 24 months in the State of Paraíba, Brazil.

\section{Methods}

A cross-sectional study conducted in 14 municipalities identified as the poorest of the state; 539 households composed of at least one child between the ages of 0 and 23.9 months were investigated. A 24-hour recall was conducted with the mothers regarding food consumed by their children. The analytic model took into account established recommendations for appropriate child feeding practices for three age groups: 0-5.9 months; 6-12 months; 12-24 months.

\section{Results}

Children between 0-5.9 months: there is a high percentage of weaning (20.7\%) and low prevalence of exclusive breastfeeding (30.5\%); children from 6-11.9 months: $45.2 \%$ of children were still breastfeeding, but only $21.7 \%$ of children between 6 and 9.9 months showed a timely complementary feeding; children between 12-23.9 months: the prevalence of weaning was $64.2 \%$. Feeding practices were characterized by high consumption of milk-based food and low consumption of food sources of iron.

\section{Conclusion}

Child feeding practices in the population studied were far from the recommendations for each stratum, indicating a risk for the food and nutritional security of this population.

Indexing terms: Food consumption. Maternal and child health. Food security.

\section{N T R O D U Ç Ã O}

O início do curso da vida, em especial nos primeiros 24 meses, é caracterizado como um dos períodos mais críticos para assegurar a segurança alimentar e nutricional (SAN) de uma população. No Brasil, segundo a Lei 11.354 de 2006, a SAN é a realização do direito de todos ao acesso regular e permanente a alimentos de qualidade, em quantidade suficiente, sem comprometer o acesso a outras necessidades essenciais, tendo como base práticas alimentares promotoras de saúde, que respeitem a diversidade cultural e que sejam ambiental, cultural, econômica e socialmente sustentáveis ${ }^{1}$. Portanto, a promoção e a garantia da SAN de uma sociedade implica uma rede complexa de fatores para a população como um todo, contemplando a disponibilidade, o acesso e o consumo de alimentos, além da utilização biológica de nutrientes ${ }^{2-3}$.
Considerando a criança e tendo em vista a imaturidade fisiológica e imunológica de seu organismo ${ }^{4}$, assim como a dependência do cuida$\mathrm{do}^{5}$, o alcance da SAN, sob determinadas condições sociais, pode ser um grande desafio. Um dos reflexos da exposição da criança a situações de Insegurança Alimentar e Nutricional (ISAN) é a desnutrição, que resulta da ação de diversos fatores de risco relacionados ao ambiente físico e social no qual a criança convive ${ }^{6,7}$.

Dentre esses fatores de risco, destaca-se a inadequada prática alimentar, em especial para as crianças residentes em regiões menos favorecidas $^{8}$, para as quais a oferta de alimentos de qualidade e em quantidade suficiente pode ser prejudicada.

A Organização Mundial de Saúde (OMS), o Ministério da Saúde do Brasil e a comunidade científica têm direcionado esforços para promover 
a alimentação saudável e adequada nos dois primeiros anos de vida, a exemplo da produção de guias alimentares para a criança com idade até 24 meses $^{9,10}$ e da formulação da Estratégia Global para Lactentes e Crianças de Primeira Infância, em $2005^{11}$. Esses documentos reforçam a importância da amamentação exclusiva nos primeiros seis meses de vida e a manutenção do aleitamento materno até os dois anos de idade, associado à introdução oportuna da alimentação complementar.

Com base nessas referências, este artigo desenvolve uma análise da prática alimentar de crianças menores de dois anos de idade residentes em municípios pobres do semiárido paraibano.

\section{MÉTOD OS}

Este estudo analisou dados da pesquisa "Avaliação da Insegurança Alimentar de Famílias Residentes no Interior do Estado da Paraíba", desenvolvida por equipe da Universidade Federal da Paraíba (UFPB), Brasil, e que contempla questões específicas sobre a prática alimentar das crianças residentes nos domicílios pesquisados.

Foi realizado um estudo secional de base populacional em 14 municípios do interior da Paraíba, dentre os 16 selecionados pelo Governo Federal em 2003 para iniciar o programa Fome Zero. Eles foram identificados, segundo o antigo Ministério Extraordinário de Segurança Alimentar (MESA), hoje Ministério do Desenvolvimento Social e Combate à Fome, como os mais carentes do interior do Estado. O indicador adotado para a seleção dos municípios foi o número de famílias abaixo da linha da pobreza'2.

Um dos municípios na condição referida foi retirado da amostra para realização do estudo-piloto e outro recusou-se a participar. Dos municípios pesquisados, um se localiza na Zona da Mata, 10 na região Agreste, dois na Borborema e um no sertão do Estado. Com relação à insegurança alimentar das famílias residentes nesses municípios, mais de $50 \%$ delas convivem com situações de ISAN, o que revela a vulnerabilidade social da região pesquisada ${ }^{13}$.

A pesquisa de campo ocorreu durante os meses de maio a agosto de 2005. Para o cálculo da amostra dos domicílios, utilizou-se a técnica de amostragem aleatória estratificada, e cada município foi dividido por área urbana e rural. Os tamanhos das amostras dos estratos foram calculados adotando-se uma partilha proporcional.

Com base nos dados populacionais do censo demográfico de 2000, foi calculada uma amostra representativa de cada município. Utilizou-se o erro amostral máximo de 5\% sob nível de confiança de $95 \%$. A estimativa esperada de segurança alimentar foi de $50 \%$ para maximizar o tamanho da amostra em cada município.

A partir dos mapas cartográficos de cada município foram sorteados aleatoriamente quarteirões na área urbana e aglomerados residenciais na área rural. O número de quarteirões necessários em cada município foi estimado de acordo com a densidade de famílias dos respectivos setores censitários. Na área rural, procurou-se visitar o maior número possível de aglomerados residenciais.

Para o estudo das práticas alimentares da criança foram considerados todos os domicílios que em sua composição apresentavam pelo menos uma criança com idade entre 0 e 23,9 meses de idade.

A pesquisa de campo contemplou entrevistas domiciliares, realizadas por entrevistadores locais. Os entrevistadores deveriam atender os requisitos de pelo menos, ensino médio completo, ter disponibilidade de tempo e não ser agente comunitário ou desenvolver alguma atividade de trabalho vinculada à secretaria de saúde. Todos foram submetidos a um treinamento de 16 horas e avaliados ao final do curso por meio de um teste de aplicação do questionário de pesquisa, sendo assim considerados aptos ou não.

Os chefes das famílias foram entrevistados no próprio domicílio sobre as características sociais e demográficas da família, e as mães ou os respon- 
sáveis pela criança foram interrogados acerca do seu consumo alimentar por meio de um recordatório 24 horas.

Todos os participantes da pesquisa assinaram um termo de consentimento livre e esclarecido antes da sua inclusão na amostra. O projeto de pesquisa foi aprovado pelo Comitê de Ética em Pesquisa do Centro de Ciências da Saúde da Universidade Federal da Paraíba na sua reunião ordinária em 17 de novembro de 2004, de acordo com a resolução 196/96 do Conselho Nacional de Saúde do Ministério da Saúde.

O estudo do consumo alimentar avaliou qualitativamente a referência da mãe/responsável sobre o consumo pelas crianças de alimentos como o leite materno, leites não maternos (leite de vaca ou modificado) e frutas; e de preparações como mingau ou papa (refeição pastosa preparada com farinha ou espessante), sopas (refeição de sal semissólida, de legumes ou carne) e comida de panela (refeição de sal, de consistência sólida, que contenha pedaços de alimentos inteiros ou amassados, e que se assemelha à comida dos adultos).

Ao final da pesquisa de campo, dos 4533 domicílios pesquisados, 539 eram compostos por pelo menos uma criança com idade entre 0 e 23,9 meses, compondo assim a amostra deste estudo.

Os dados resultantes desta pesquisa foram digitados por meio do utilitário Access do pacote Office for Windows, e as análises foram realizadas com o auxílio da plataforma estatística Statistical Package for the Social Sciences (SPSS) for Windows 11.0 e Epi info 6.0.

Foi realizada uma caracterização da amostra segundo a idade da criança, a situação do domicílio, a idade e a escolaridade maternas. Para fins de análise sobre a prática alimentar, admitiu-se que durante os dois primeiros anos de vida a criança passa por três momentos distintos em seu crescimento e desenvolvimento, os quais exigem práticas alimentares diversas. Esses momentos foram aqui delimitados pelo ponto de corte da idade da criança, considerando-se ainda as diferenças nas recomendações para seu consumo alimentar.
A seguir são apresentados os momentos considerados e o critério de análise de dados adotados neste estudo:

- Primeiro momento: aleitamento materno exclusivo (crianças de 0 a 5,9 meses).

Tendo em vista o consenso existente sobre as propriedades do leite materno e seus efeitos para o pleno desenvolvimento infantili ${ }^{11}$, recomenda-se a prática do Aleitamento Materno Exclusivo (AME) até os seis meses de idade ${ }^{9}$.

Nessa perspectiva, avaliou-se a frequência do aleitamento materno na amostra de crianças com até 5,9 meses de idade, classificadas em três faixas etárias (0-1,9 meses; 2,0-3,9 meses; 4,0-5,9 meses). Considerou-se que estavam em Aleitamento Materno Total (AMT) todas as crianças que consumiam leite materno, independentemente do consumo de outros alimentos. Foram adotadas ainda as seguintes categorias:

Aleitamento Materno Exclusivo (AME): crianças alimentadas somente pelo leite materno, diretamente da mama ou extraído ${ }^{10}$.

Aleitamento Materno Predominante e Misto (AMP/AMM): criança que recebe, além do leite materno, água, chás e/ou outro tipo de leite ${ }^{10}$.

Aleitamento Materno Complementado (AMC): criança que recebe leite materno, complementado com alimentos típicos do consumo familiar.

- Segundo momento: amamentação associada à introdução gradativa dos alimentos (crianças de 6 a 11,9 meses).

A partir dos seis meses de idade, a maioria das crianças atinge um estágio de desenvolvimento geral e neurológico que torna necessário o consumo de outros alimentos que não apenas o leite materno ${ }^{8}$. Dessa forma, a análise desse momento teve como principal aspecto a introdução dos diferentes tipos de alimentos e preparações em tempo oportuno ${ }^{9}$. Portanto, as crianças da amostra foram classificadas quanto às categorias de aleitamento materno e introdução 
de alimentos (refeições lácteas, compostas por mingaus, papas e/ou leite não materno; sopas e comida de panela).

O indicador de Alimentação Complementar Oportuna (ACO), proposto pela OMS ${ }^{13}$, recomenda para as crianças entre 6 e 9,9 meses a continuidade da amamentação acrescida do consumo de alimentos sólidos ou semissólidos, tendo sido um dos parâmetros adotados. Assim, foram consideradas em ACO as crianças entre 6 e 9,9 meses que no dia anterior à entrevista haviam consumido leite materno e pelo menos uma refeição de sal sólida (comida de panela) e/ou semissólida (sopas).

- Terceiro momento: aleitamento materno complementado (crianças de 12 a 23,9 meses).

Durante o segundo ano de vida, o leite materno prossegue sendo importante para a nutrição da criança, devendo ser complementado com o consumo de alimentos típicos da família9 .

A análise desse momento se desenvolveu com a classificação das crianças nas categorias de aleitamento materno, quantificação do número de refeições e descrição dos principais alimentos e preparações consumidas no dia anterior à entrevista, com destaque para alguns aspectos qualitativos, como consistência e consumo de alimentos fontes de ferro.

No tocante ao número de refeições, a OMS recomenda que as crianças nessa faixa de idade realizem três refeições principais durante o dia, somadas a pelo menos dois ou três lanches nos intervalos. Para essa análise, considerou-se o consumo da manhã, almoço e jantar como refeições principais, e como lanches, o consumo no período da tarde, noite e madrugada ${ }^{14}$.

\section{RE S U LT A DOS}

A amostra estudada foi composta de 539 crianças, sendo $30,4 \%$ de menores de seis meses de idade, $25 \%$ entre 6 e 11, 9 meses e $44,5 \%$ entre 12 e 23,9 meses. A distribuição das crianças por situação de domicílio foi semelhante entre as zonas urbana e rural (Tabela 1).

Um percentual importante de mães tinha menos de 20 anos, especialmente para as crianças mais jovens. Para os três grupos de crianças, destaca-se ainda que mais de $50 \%$ das mães refe-

Tabela 1. Distribuição (\%) de variáveis sociodemográficas, por estrato etário, de crianças menores de dois anos em municípios da Paraíba, Brasil, 2005.

\begin{tabular}{|c|c|c|c|c|c|c|}
\hline \multirow{2}{*}{ Variáveis } & \multicolumn{2}{|c|}{$0-5,9$ meses $^{*}$} & \multicolumn{2}{|c|}{$6-11,9$ meses $^{* *}$} & \multicolumn{2}{|c|}{$12-23,9$ meses $^{* * *}$} \\
\hline & $\mathrm{n}$ & $\%$ & $\mathrm{n}$ & $\%$ & $n$ & $\%$ \\
\hline Total de crianças ( $n=539$ ) & 164 & 30,4 & 135 & 25,0 & 240 & 44,5 \\
\hline Média de idade da criança & \multicolumn{2}{|c|}{2,91} & \multicolumn{2}{|c|}{9,27} & \multicolumn{2}{|c|}{17,67} \\
\hline \multicolumn{7}{|l|}{ Situação do domicílio } \\
\hline Urbano & 79 & 48,2 & 6 & 46,2 & 114 & 47,5 \\
\hline Rural & 85 & 51,8 & 74 & 54,8 & 126 & 52,5 \\
\hline \multicolumn{7}{|l|}{ Faixa de idade materna } \\
\hline$=<20$ anos & 35 & 21,3 & 34 & 25,2 & 35 & 14,6 \\
\hline$>20$ anos & 126 & 76,8 & 99 & 73,3 & 199 & 82,9 \\
\hline \multicolumn{7}{|l|}{ Escolaridade } \\
\hline Sem escolaridade & 25 & 15,2 & 23 & 17,0 & 39 & 16,3 \\
\hline Ensino primário incompleto ${ }^{* * * *}$ & 67 & 40,9 & 56 & 41,5 & 107 & 44,6 \\
\hline Ensino primário completo ${ }^{* * * * *}$ & 67 & 40,9 & 53 & 39,3 & 91 & 37,9 \\
\hline Não sabe/respondeu & 5 & 3,0 & 3 & 2,2 & 3 & 1,3 \\
\hline
\end{tabular}

"Três casos sem informação em idade materna; ${ }^{* *}$ Três casos sem informação em idade materna; ${ }^{* *}$ Cinco casos sem informação em idade materna; ${ }^{* * * *}$ Mães que não concluíram o ensino primário (8 série); ${ }^{* * * *}$ Mães que concluíram o ensino primário, secundário incompleto ou completo, curso técnico ou superior. 
riram ausência de escolaridade ou ensino primário incompleto.

A seguir serão apresentados os resultados referentes às práticas alimentares das crianças estudadas.

- Primeiro momento: aleitamento materno exclusivo (crianças de 0 a 5,9 meses de idade).

Até os 5,9 meses de idade, 20,7\% das crianças já não consumiam o leite materno e apenas 30,5\% se alimentavam deste exclusivamente (Tabela 2).

A Figura 1 mostra as diferenças nos percentuais de AMT e AME entre subgrupos etários. Cabe destacar a redução desses percentuais à medida que a idade das crianças aumenta. Assim, no grupo estudado, mais de $94 \%$ das crianças estavam em AMT nos primeiros dois meses de vida e 50,9\% estavam em AME. No grupo de crianças com idade entre 4 e 5,9 meses, no entanto, 65,2\% das crianças estavam em AMT e 10,4\% em AME.

- Segundo momento: amamentação associada à introdução gradativa dos alimentos (crianças de 6 a 11,9 meses).

Para as crianças com idade entre 6 e 11,9 meses, encontrou-se uma prevalência de 45,2\% de AMT, e, dentre essas, 83,6\% realizavam a prática do aleitamento materno complementada com alimentos típicos da família (Tabela 2).

Segundo o indicador ACO, apenas 21,7\% das crianças com idade entre 6 e 9,9 meses experimentaram a introdução oportuna de alimentos complementares, ou seja, mantiveram o consumo do leite materno associado a alguma refeição de sal.

A Figura 2 mostra o percentual de consumo de refeições lácteas, sopas e comida de panela entre as crianças de 6 a 11,9 meses de idade. Destaca-se o alto consumo de refeições do tipo lácteas (85,9\%). A oferta da comida de panela apresentou-se maior entre as crianças com idade entre 10 e 11,9 meses, entretanto esses índices não superam a escolha por refeições à base de leite.

- Terceiro momento: aleitamento materno complementado (crianças de 12 a 23,9 meses).

Durante o segundo ano de vida, não se observou no grupo estudado a manutenção da prática do aleitamento materno. Os percentuais de AMC (33,3\%) são reduzidos, destacando-se a alta prevalência de desmame (64,2\%) (Tabela 2).

As prevalências de AMT, conforme observado nos grupos etários anteriores, apresentaram redução com o aumento da idade das crianças. Aos 15 meses de idade, essa redução é mais acentuada, e, ao final do segundo ano de vida, apenas 9,3\% das crianças ainda consomem o leite materno.

Sobre a prática alimentar durante o dia que antecedeu a entrevista, o alimento mais referido foi o leite não materno (73,8\%), seguido do pão e da bolacha $(64,2 \%)$ e mingau ou papa $(60,4 \%)$ (Figura 3). Outros alimentos e preparações também foram citados, como frutas $(50,0 \%)$ e comida de panela com feijão $(55,4 \%)$.

Tabela 2. Distribuição, em porcentagem, em categorias, do consumo de leite materno referido, por estrato etário, de crianças menores de dois anos em municípios da Paraíba, Brasil, 2005.

\begin{tabular}{|c|c|c|c|c|c|c|}
\hline \multirow{2}{*}{ Categorias de Aleitamento Materno } & \multicolumn{2}{|c|}{$0-5,9$ meses } & \multicolumn{2}{|c|}{$6-11,9$ meses } & \multicolumn{2}{|c|}{$12-23,9$ meses } \\
\hline & $\mathrm{n}$ & $\%$ & $\mathrm{n}$ & $\%$ & $\mathrm{n}$ & $\%$ \\
\hline Aleitamento Materno Exclusivo* & 50 & 30,5 & 2 & 1,5 & 2 & 0,8 \\
\hline Aleitamento Materno Predominante ou Misto** & 46 & 28,0 & 8 & 5,9 & 4 & 1,7 \\
\hline Aleitamento Materno Complementado*** & 34 & 20,8 & 51 & 37,8 & 80 & 33,3 \\
\hline Aleitamento Materno Total $\left.\right|^{* \star * *}$ & 130 & 79,3 & 61 & 45,2 & 86 & 35,8 \\
\hline Desmame $e^{* \star * * *}$ & 34 & 20,7 & 74 & 54,8 & 154 & 64,2 \\
\hline
\end{tabular}

* Criança alimentada somente pelo leite materno, diretamente da mama ou extraído; ${ }^{* *}$ Criança que recebe, além de leite materno, água, chás e/ou outros tipos de leite; ${ }^{* * *}$ Criança que recebe leite materno, complementado com alimentos típicos do consumo familiar; ${ }^{* * * *}$ Crianças alimentadas pelo leite materno, independente do consumo de outros alimentos; ${ }^{* * * *}$ Crianças que não são alimentadas pelo leite materno. 


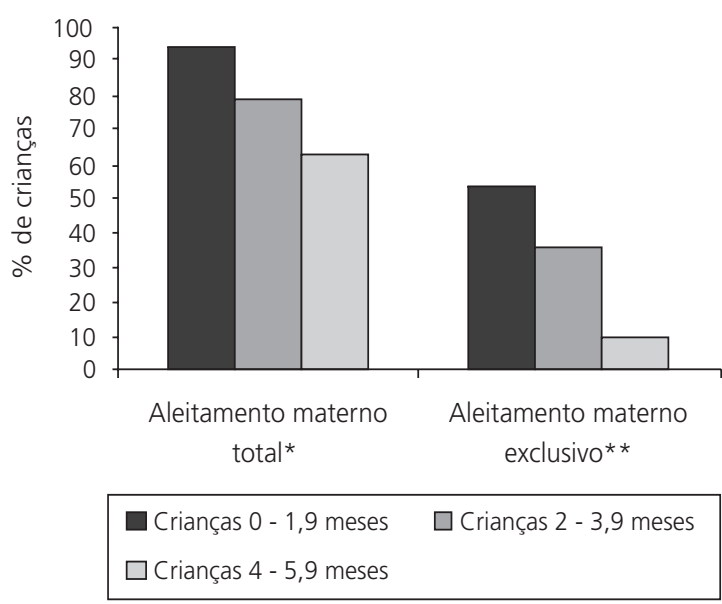

Figura 1. Prevalência de aleitamento materno total e aleitamento materno exclusivo em crianças menores de seis meses e por estrato etário, em municípios da Paraíba, Brasil, 2005.

Nota: * Criança alimentada somente pelo leite materno, diretamente da mama ou extraído; ${ }^{* *}$ Crianças alimentadas pelo leite materno, independente do consumo de outros alimentos.

Fonte: Recordatório de 24 horas.

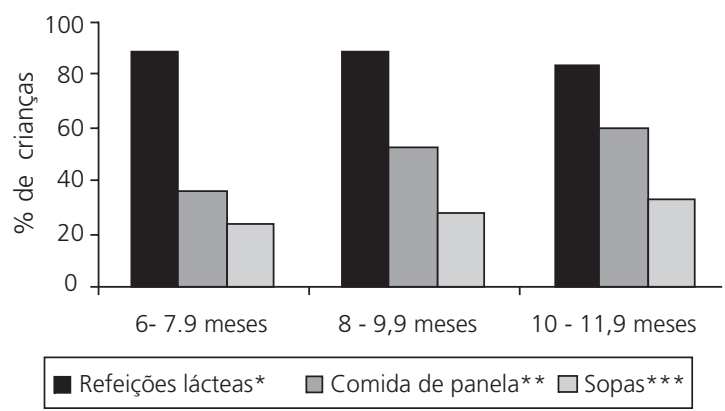

Figura 2. Distribuição percentual de respostas sobre consumo de refeições lácteas, alimentos da família e sopas, de crianças entre 6-11,9 meses de idade em municípios da Paraíba, Brasil, 2005.

Nota: *Referência ao consumo de leite de vaca, em pó ou fluido, leite modificado e preparação à base de leite, espessantes ou farináceos.; ${ }^{* *}$ Referência ao consumo de refeições de sal de consistência sólida, em pedaços ou amassadas, e que se assemelham à alimentação dos adultos; ${ }^{* * *}$ Referência ao consumo de refeições de sal semissólidas.

Fonte: Recordatório 24 horas.

Ao analisar apenas o consumo alimentar do almoço, refeição que pode ser considerada uma das principais da alimentação infantil, os dados mostraram que $50,4 \%$ das mães relataram preferência pelos alimentos comuns à família

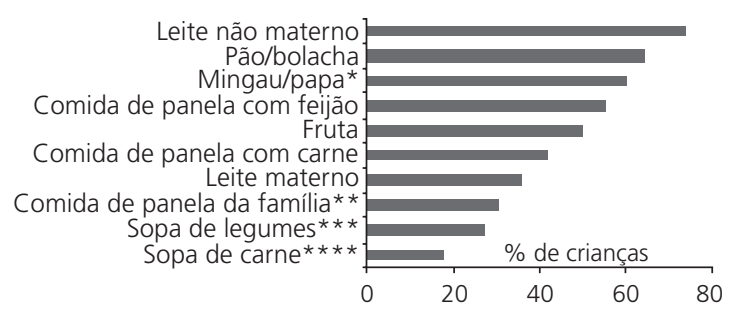

Figura 3. Distribuição percentual de respostas sobre consumo de diferentes alimentos e preparações, de crianças entre 12-23,9 meses de idade em municípios da Paraíba, Brasil, 2005.

Nota: * Referência do consumo de refeições pastosa preparada com farinha ou espessante; ${ }^{* *}$ Referência ao consumo de refeições de sal de consistência sólida, em pedaços ou amassadas, e que se assemelham à alimentação dos adultos; ${ }^{* * *}$ Referência ao consumo de refeições de sal semissólidas, com legumes; ${ }^{* * * *}$ Referência ao consumo de preparações de sal semissólidas, com carne.

Fonte: Recordatório 24 horas.

acrescidos do feijão, enquanto outras relataram ofertar esses alimentos com adição de carne (36,7\%). Destaca-se um importante consumo de leite não materno nessa refeição: $32,6 \%$ das mães entrevistadas afirmaram haver o consumo de preparações lácteas pelas crianças no horário do almoço.

Com relação ao consumo de preparações ricas em ferro, $70 \%$ das crianças consumiram no dia anterior à entrevista preparações com carne e/ou feijão, sendo a escolha pelo feijão mais expressiva.

Observou-se ainda que menos do que $5,0 \%$ das crianças se alimentaram menos de três vezes ao dia, enquanto $30,8 \%$ das mães referiram 3 ou 4 refeições e/ou lanches ao dia, e a grande maioria $(65,5 \%), 5$ ou 6 .

\section{DIS C U S S Ã O}

- Primeiro momento: aleitamento materno exclusivo (crianças de 0-5,9 meses de idade).

O padrão alimentar analisado nesse estágio do crescimento infantil aponta para a reduzida prática do aleitamento materno na amostra estudada. Ainda assim, as prevalências de AME en- 
contradas foram superiores às referenciadas por Vianna et al. ${ }^{15}$, para municípios do interior do Estado da Paraíba, e por Kitoko et al. ${ }^{16}$, para a capital do Estado em 1997. Nesse contexto, registrou-se a precocidade com que os alimentos complementares foram introduzidos na alimentação da criança, e a consequente redução do número de crianças em AMT e AME. Esse quadro também é assinalado em outros estudos realizados no Nordeste do Brasil e em populações vulneráveis ${ }^{17-19}$.

Além disso, de acordo com Nejar et al. ${ }^{20}$, em estudo realizado em Campinas (SP), a duração e a frequência das mamadas de crianças menores de 6 meses em AME são superiores as de crianças em AMC nessa mesma faixa de idade, sugerindo que a introdução inoportuna dos alimentos complementares pode acelerar o processo de desmame.

Dessa forma, nos primeiros seis meses de vida, a prática alimentar das crianças paraibanas estudadas parece ter se constituído em fator de risco para a ISAN pela associação de dois fatores diretamente interligados: a não realização do direito à amamentação e o consumo precoce de alimentos complementares.

Os determinantes da interrupção precoce da AME são discutidos na literatura científi$\mathrm{ca}^{15,19,21,22}$, com destaque para a baixa escolaridade e trabalho materno, e falta de acesso a informações que incentivem a prática do aleitamento materno. Considerando as características da amostra estudada, pressupõe-se que alguns desses fatores possam estar presentes, influenciando a provisão de cuidados adequados para a criança.

- Segundo momento: amamentação associada à introdução gradativa dos alimentos (crianças de 6 a 11,9 meses de idade).

Entre as crianças de 6 a 11,9 meses de idade, o direito de usufruir dos benefícios do leite materno continua a ser negado. Aliado a isso, com o início da formação do hábito alimentar da criança e o processo de introdução dos alimentos complementares, observa-se que surge outro ele- mento da prática alimentar inadequada: a escolha preponderante de alimentos semissólidos à base de leite não materno, em detrimento de uma aproximação gradativa aos alimentos típicos da família.

Quanto à prática do aleitamento materno total, os percentuais encontrados neste estudo corroboram os obtidos na pesquisa desenvolvida por Monteiro et al. ${ }^{23}$ nos municípios do semiárido paraibano, na qual foram encontradas cerca de $50 \%$ das crianças em AMT.

O percentual de crianças em ACO $(21,7 \%)$ foi inferior ao encontrado por pesquisas realizadas na capital do Estado da Paraíba ${ }^{16}$ (39,0\%) e à média encontrada em outras capitais nordestinas $^{24}(43,5 \%)$. Possivelmente esse resultado tenha sido determinado não apenas pelo baixo consumo do leite materno, mas principalmente pelo reduzido consumo de refeições de sal devido à preferência das mães por refeições lácteas.

A significativa participação das refeições à base de leite não materno na alimentação das crianças nessa faixa de idade também foi destacada por outros pesquisadores $22,25,26$. Acredita-se que, além da facilidade de acesso e da disponibilidade do leite não materno e dos espessantes para as populações mais vulneráveis, essa escolha também esteja enraizada na cultura materna, caracterizada pela valorização desses alimentos na dieta da criança ${ }^{10}$.

Além desses fatores, a permanência de propagandas na mídia televisiva incentiva o consumo do leite não materno, apesar da adoção da Norma Brasileira de Comercialização de Substitutos do Leite Materno, conforme Rea ${ }^{27}$.

A expressiva escolha por alimentos de consistência pastosa ou semissólida encontrada neste estudo pode caracterizar-se como um fator de exposição para a ISAN e para deficits de crescimento e desenvolvimento da criança. O baixo consumo de refeição do tipo sólida sugere a ingestão de preparações com reduzida densidade energética e pobre em alimentos de origem animal, o que prejudica o aporte calórico ${ }^{10}$. 
- Terceiro momento: aleitamento materno complementado (crianças de 12 a 23,9 meses).

Também entre as crianças dessa faixa etária destacou-se a baixa prevalência do consumo de leite materno. A isso se acresce o insuficiente consumo de alimentos de fundamental importância para a dieta da criança, como frutas, legumes, leguminosas e alimentos de origem animal.

Sendo assim, a reduzida qualidade nutricional dos alimentos consumidos pelas crianças estudadas nesse grupo revelou-se como um dos principais aspectos da prática alimentar inadequada.

O leite não materno e os alimentos ricos em carboidratos simples, representados por espessantes, bolachas e pães, caracterizaram a base da alimentação dessas crianças. A grande participação desses alimentos na composição da dieta de crianças nordestinas já foi apontada por estudos em outros estados do Nordeste, como Bahia e Pernambuco ${ }^{25,26}$.

Estudos atuais têm indicado que o leite de vaca quando consumido juntamente com alimentos fontes de ferro pode reduzir a absorção desse micronutriente ${ }^{28-30}$ e facilitar a exposição a situações de ISAN.

Dessa forma, o consumo de preparações à base de leite não materno, sobretudo em refeições como o almoço, e a dificuldade de acesso aos alimentos fontes de ferro em populações menos favorecidas configuram-se como riscos ao desenvolvimento da anemia ferropriva, doença carencial de alta prevalência entre as crianças brasileiras $^{28}$.

\section{O N CLUS Ã O}

O presente estudo reuniu crianças de três faixas etárias, partindo do pressuposto de que os elementos da prática alimentar que se configuram como fatores de exposição dessas crianças a ISAN podem ser diferenciados. Observou-se no grupo estudado a ocorrência de dois processos simultâneos que expressam riscos para a SAN da crian- ça: a interrupção precoce do consumo do leite materno e a introdução inadequada de alimentos, representada pelo consumo de refeições lácteas em detrimentos das refeições de sal.

A avaliação isolada da prática alimentar é insuficiente para compreender e explicar o fenômeno da SAN entre crianças; outros fatores, como a provisão de cuidados adequados e a disponibilidade de recursos no domicílio, podem ser determinantes na realização de uma prática alimentar segura, especialmente em grupos inseridos em regiões de vulnerabilidade.

Nesse sentido, é de fundamental importância a realização de estudos mais abrangentes que possam identificar muitas das nuances da ISAN e SAN para o grupo das crianças menores de dois anos de idade. Não obstante, estudos desta natureza contribuem para a formulação de estratégias locais, embasando a formulação de políticas públicas e programas de alimentação e saúde.

\section{A GRADECIMENTOS}

Ao Conselho Nacional de Desenvolvimento Científico e Tecnológico (CNPq) pelo financiamento (Processo 503359/03-3) e pela bolsa de iniciação científica dos estudantes que participaram do projeto; à Coordenação de Aperfeiçoamento do Pessoal do Ensino Superior (CAPES) pela bolsa de mestrado demanda social de Poliana Palmeira; à equipe de campo; e a todas as famílias, pelo apoio e colaboração.

\section{COLABORADORES}

P.A. PALMEIRA participou da pesquisa de campo, analisou os dados e redigiu o manuscrito. S.M.C. SANTOS participou da interpretação dos dados e redação do manuscrito. R.P.T. VIANNA planejou e coordenou a coleta de dados.

\section{REFERÊNCIAS}

1. Brasil. Lei $n^{\circ} 11.346$ de 15 de setembro de 2006 . Lei Orgânica de Segurança Alimentar e Nutricional. 
[acesso em 2007 dez 11]. Disponível em: <htttp:// www. planalto.gov.br/consea/static/eventos/ losan.htm>.

2. Rogers B. La medición y monitoreo de la inseguridad alimentaria: consideraciones para el desarrollo de un indicador. In: Peréz-Escamilla $R$, Uribe MCA, Segall-Corrêa AM, Melgar-Quiñónez $H$. Perspectivas en nutrición humana: Memorias de la I Conferencia en América Latina y el Caribe sobre a la Medición de la Seguridad Alimentaria en el Hogar, 2007 Antioquia, Colombia: Universidad de Antioquia; 2007. p.117-34.

3. Brasil. Conselho Nacional de Segurança Alimentar e Nutricional. Relatório final da II Conferência Nacional de Segurança Alimentar e Nutricional. Olinda: MS; 2004 [acesso 2007 nov 12]. Disponível em: <www.fomezero.gov.br/download/relatorio_ final_IICNSAN.pdf>.

4. Mahan, LK, Escott-Stump S. Krause: alimentos, nutrição e dietoterapia. $11^{a}$ ed. São Paulo: Roca; 2005.

5. Oliveira VA, Barreto ML, Assis AMO, Braga-Junior ACR, Nunes MFF, Oliveira NF, et al. Preditores do retardo de crescimento linear em pré-escolares: uma abordagem multinível. Cad Saúde Pública. 2007; 23(3):601-13. doi: 10.1590/S0102-311X20 07000300019.

6. Olinto MTA, Victora CG, Barros FC, Tomasi E. Determinantes da desnutrição infantil em uma população de baixa renda: um modelo hierarquizado. Cad Saúde Pública. 1993; 9(Suppl. 1):S14-S27. doi: 10.1590/S0102-311X1993000500003.

7. Issler RMS, Giugliani ERJ. Identificação de grupos mais vulneráveis a desnutrição infantil pela medição do nível de pobreza. J Pediatr. 1997; 73(2):101-5.

8. Monte CMG, Giugliani ERJ. Recomendações para alimentação complementar da criança em aleitamento materno. J Pediatr. 2004; 80(Suppl. 5): S131-S41.

9. World Health Organization. Guiding principles for complementary feeding of the breastfed child. Washington (DC): WHO; 2003.

10. Brasil. Ministério da Saúde. Guia alimentar para crianças menores de dois anos. Brasília (DF): Ministério da Saúde; 2002. Serie A. Normas e manuais técnicos.

11. Organização Mundial de Saúde. Estratégia global para a alimentação de lactentes e crianças de primeira infância. In: I Encontro Nacional sobre Segurança Alimentar e Nutricional na Primeira Infância, São Paulo, SP, Brasil, 2005. São Paulo: Baby Food Action Network; 2005.

12. Instituto Cidadania. Projeto Fome Zero: uma proposta de política de segurança alimentar para o
Brasil. São Paulo: MDS 2001 [acesso $2011 \mathrm{fev} 11$ ]. Disponível em: <www.fomezero.gov.br/download/ livro_projeto\%20fome.pdf>.

13. Vianna RPT, Segall-Corrêa, AM Insegurança alimentar das famílias residentes em municípios do interior do estado da Paraíba, Brasil. Rev Nutr. 2008; 21(Suppl):111s -122s. doi: 10.1590/S1415-52732 008000700010.

14. World Health Organization. Report of: Informal meeting to review and develop indicators for complementary feeding. Washington (DC): WHO; 2002 [cited em 2007 jun 10]. Availble from: <http:// www.who.int/nutrition/publications/infantfeeding/ a91059/en/index.html>.

15. Vianna RPT, Rea MF, Venancio SI, Escuder MM. A prática de amamentar entre as mulheres que exercem trabalho remunerado na Paraíba, Brasil: um estudo transversal. Cad Saúde Pública. 2007; 23(10):2403-9. doi: 10.1590/S0102-311X200700 1000015 .

16. Kitoko PM, Rea MF, Venancio SI, Vasconcelos ACC, Santos EKA, Monteiro CA. Situação do aleitamento materno em duas capitais brasileiras: uma análise comparada. Cad Saúde Pública. 2000; 16(4):1111-9. doi: 10.1590/S0102-311X2000000400029.

17. Oliveira LPM, Assis AMO, Gomes GSS, Prado MS, Barreto ML. Duração do aleitamento materno, regime alimentar e fatores associados segundo condições de vida em Salvador, Bahia, Brasil. Cad Saúde Pública. 2005; 21(5):1519-30. doi: 10.1590/S0-10 2-311X2005000500025.

18. Silveira FJF, Lamounier JA. Prevalência do aleitamento materno e práticas de alimentação complementar em crianças com até 24 meses de idade na região do Alto Jequitinhonha, Minas Gerais. Rev Nutr. 2004; 17(4):437-47. doi: 10.1590/S1415-52 732004000400004.

19. Vasconcelos MGL, Lira PIC, Lima MC. Duração e fatores associados ao aleitamento materno em crianças menores de 24 meses de idade no estado de Pernambuco. Rev Bras Saúde Matern Infant. 2006; 6(1):99-105. doi: 10.1590/\$1519-3829200 6000100012.

20. Nejar FF, Segall-Corrêa AM, Rea MF, Vianna RPT, Panigassi G. Padrões de aleitamento materno e adequação energética. Cad Saúde Pública. 2004; 20(1):64-71. doi: 10.1590/S0102-311X20040001 00020.

21. Vieira MLF, Pinto e Silva JLC, Barros Filho AA. A amamentação e a alimentação complementar de filhos de mães adolescentes são diferentes das de filhos de mães adultas? J Pediatr. 2003; 79(4):317-24.

22. Saldiva SRDM, Escuder MM, Mondini L, Levy RB, Venancio SI. Práticas alimentares de crianças de 6 a 12 meses e fatores materno associados. J Pediatr. 
2007: 83(1):53-8. doi: 10.1590/S0021-75572007 000100010.

23. Monteiro CA, Conde WL, Konno SC. Análise do inquérito "Chamada Nutricional 2005" realizado pelo Ministério do Desenvolvimento Social e Combate à Fome e Ministério da Saúde. São Paulo: USP; 2006 [acesso 10 dez. 2007]. Disponível em: <http://www.planalto.gov.br/consea/static/ documentos/Outros/chamada 2005.pdf>.

24. Brasil. Ministério da Saúde. Pesquisa prevalência de aleitamento materno nas capitais brasileiras e no Distrito Federal. Brasília: MS; 2001 [acesso 2007 nov. 20]. Disponível em: <http://www.bvsam. icict.fiocruz.br>.

25. Oliveira LPM, Assis AMO, Pinheiro SMC, Prado MS, Barreto ML. Alimentação complementar nos primeiros dois anos de vida. Rev Nutr. 2005. 18(4): 459-69. doi: 10.1590/S1415-5273200500040 0002.

26. Farias JG, Osório MM. Padrão alimentar de crianças menores de cinco anos. Rev Nutr. 2005; 18(6): 793-802. doi: 10.1590/S1415-5273200500060 0010.
27. Rea MF. Reflexões sobre a amamentação no Brasil: de como passamos a 10 meses de duração. Cad Saúde Pública. 2003; 19(Suppl 1):37-45 doi: 10.15 90/S0102-311X2003000700005.

28. Levy-Costa RB, Monteiro CA. Cow's milk consumption and childhood anemia in the city of São Paulo, southern Brazil. Rev Saúde Pública. 2004; 38(6):797-803. doi: 10.1590/S0034-8910 2004000600007.

29. Oliveira MA, Osório MM. Consumo de leite de vaca e anemia ferropriva na infância. J Pediatr (Rio de Janeiro). 2005; 81(5):361-7. doi: 10.1590/S0021-7 5572005000600004.

30. Batista-Filho $M$, Rissin A. A transição nutricional no Brasil: tendências regionais e temporais. Cad Saúde Pública. 2003; 19(Suppl. 1):S181-S91. doi: 10.1590/S0102-311X2003000700019.

Recebido em: 5/5/2010

Versão final reapresentada em: 14/2/2011 Aprovado em: 28/3/2011 